\title{
Successful resection of hepatocellular cancer not amenable to Milan criteria and durable complete remission induced by systemic polichemotherapy after development of metastases - should we think about revising the current treatment guidelines in selected patients?
}

Ivana Rados ${ }^{1}$, Sasa Badzek², Hilda Golem², Juraj Prejac ${ }^{2}$, Irma Gorsic ${ }^{2}$, Domina Kekez ${ }^{2}$, Niksa Librenjak² and Stjepko Plestina ${ }^{2}$

\begin{abstract}
Objectives: To refresh clinical diagnostic and therapeutic dilemmas in patients presenting with hepatocellular cancer (HCC) and to report a rare success of systemic polichemotherapy in metastatic HCC.
\end{abstract}

Methods: Case report of a patient with successfully resected HCC although initially deemed inoperable according to current guidelines, and who was successfully treated by systemic polichemotherapy after development of metastatic disease, resulting in a sustained complete remission.

Results: We describe a 71-year-old female with HCC initially treated by atypical liver resection, although not amenable to initial surgery according to current treatment guidelines, which resulted in 6 months disease-free interval. After development of pulmonary metastases, the patient was treated by systemic polichemotherapy, due to local unavailability of novel biologic agents. After 3 months of chemotherapy biochemical remission was confirmed, and after 10 months of active treatment complete radiological remission was verified according to Response Evaluation Criteria in Solid Tumors (RECIST) criteria, now exceeding 9 months in duration.

Conclusion: There is an increasing body of evidence that criteria for surgical interventions in HCC should be revised and expanded, and our case is an example of such an approach. Although novel biologic therapies are not widely available in all regions of the world due to their cost, currently there are no hard recommendations for use of chemotherapy in such areas. Since this is a large problem in clinical practice, we conclude that chemotherapy should be offered to selected patients of good performance status if novel agents are unavailable.

\footnotetext{
* Correspondence: sbadzek@kbc-zagreb.hr

${ }^{2}$ Department of Oncology, Division of Gastrointestinal Malignancies,

University Hospital Center Zagreb, Kispaticeva 12, 10000, Zagreb, Croatia

Full list of author information is available at the end of the article
} 


\section{Background}

Cancer of the liver is one of most common malignancies worldwide [1]. It emerges in fields of carcinogenesis in cirrhotic liver due to any cause, and therefore is one of paradigms of viral causes of cancer [2-7]. Other risk factors implied include chronic alcohol consumption, metabolic liver diseases, cryptogenic cirrhosis, and aflatoxin B1 [8,9]. It can also occur sporadically in patients without any identifiable cause, in approximately $20 \%$ of cases.

Since its common presentation is in patients with severe liver dysfunction, it is one of the deadliest cancers as well as one of the cancers which are hardest to treat.

In patients with localized disease, main 'curative' treatment modalities are surgery, embolization, chemoembolization, radiofrequency ablation and orthotopic liver transplantation, with liver transplantation being most beneficial in terms of survival, although some controversy exists whether radical resection should be the treatment of choice $[10,11]$. Thirty to forty percent of patients with localized disease are deemed eligible for curative intention and are selected according to Milan criteria, although recently there are published data suggesting that these criteria should be expanded [12,13].

However, in patients with metastatic disease, treatment options remain limited. Historically, chemotherapy was the only hope for prolongation of life in these patients, and polichemotherapy has not been shown to be beneficial in terms of survivorship compared to doxorubicin alone, although better response rates have been reported [14]. One of the possible reasons is presentation of disease in patients with severe comorbidities. With the emergence of novel biologic agents, primarily sorafenib, response rates became higher and overall survival has practically doubled, but still remains disappointingly low [15-17].

Novel biologic agents are very expensive, and therefore are not yet available in all parts of the world.
Recommendations of the European Society of Medical Oncology suggest use of chemotherapy in regions where no other options are available in medically fit patients [18].

We present a case of sporadic hepatocellular cancer (HCC), radically resected although not amenable to Milan criteria, and successfully treated with systemic chemotherapy after development of metastatic disease, producing durable complete remission.

\section{Case presentation}

A 71-year-old female diabetic patient was diagnosed with incidental liver mass during liver ultrasound undertaken for other reasons in a small regional hospital. Initial alphafetoprotein (AFP) was $>5000 \mathrm{ng} / \mathrm{ml}$, and after adequate radiological evaluation (3-phase computed tomography scan) diagnosis of $\mathrm{HCC}$ was established, consisting of four liver nodules larger than $5 \mathrm{~cm}$. No risk factors for $\mathrm{HCC}$ development were identified. Histological confirmation of the diagnosis was made, and the patient was referred to the experienced center (Figure 1). The tumor was classified as cT3aN0M0, IIIA stage. According to Milan criteria, the patient was not a candidate for liver transplantation. Since she was of excellent overall performance status and had no signs of chronic liver disease, atypical liver resection was attempted. According to the pathohistological review, surgical resection was adequate, ensuring $>1 \mathrm{~cm}$ margin. Since no signs of the disease were found during postoperative re-evaluation, no further action was undertaken. After 6 months follow-up, and increase in AFP level was detected, and multiple pulmonary metastases were confirmed on consequent computed tomography and positron emission tomography scan (Figure 2). The patient was further treated with polichemotherapy according to the modified ECF regimen (epirubicin $50 \mathrm{mg} / \mathrm{m}^{2}$ on day 1 , cisplatin $60 \mathrm{mg} / \mathrm{m}^{2}$ on day 1 , and 5 -fluorouracil $840 \mathrm{mg} / \mathrm{m}^{2}$ on days 1 to 5 , given as a 21-day cycle). After three cycles of chemotherapy, biochemical remission was confirmed and radiological evaluation revealed a partial

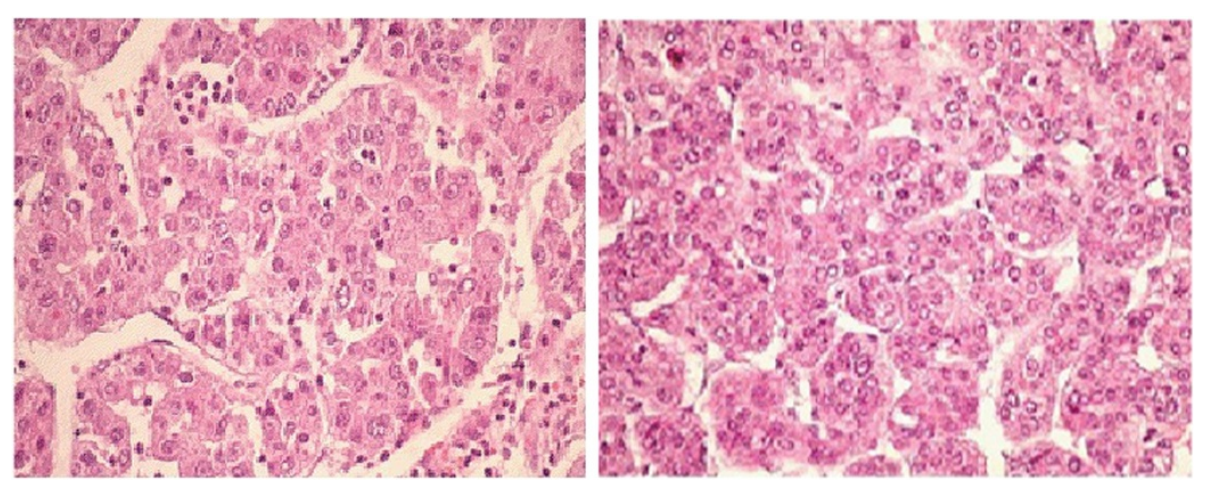

Figure 1 Pathohistological review of hepatocellular cancer. Clusters and trabeculae of atypical hepatocytes with hyperchromatic nuclei and angioinvasion are visible, surrounded by healthy liver tissue. Hematoxylin-eosin stain, magnification 400x, of bioptic pathohistological samples. 


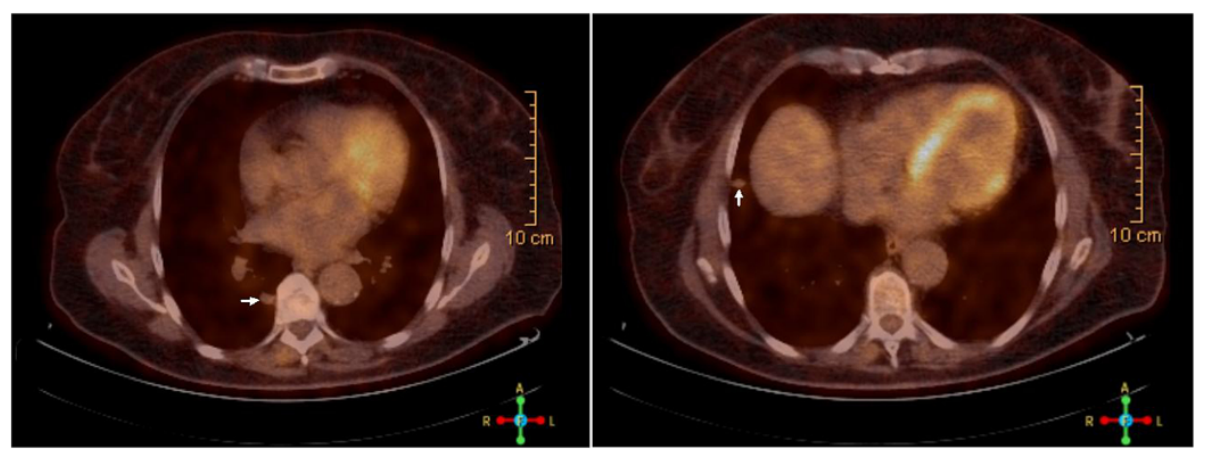

Figure 2 Fluorodeoxyglucose-positron emission tomography scan of pulmonary metastases. PET scan images reveal two larger metastases in the right lung: paravertebral (maximal Standardized Uptake Value $=1.9,16 \mathrm{~mm}$ largest diameter) and peripheral subcostal (maximal Standardized Uptake Value $=2.9,13 \mathrm{~mm}$ diameter), as indicated by white arrows. A few smaller nodules (fluorodeoxyglucose-positron emission tomography scan negative) in both lungs are also visible.

response. Chemotherapy was continued up to 11 cycles, when complete radiological remission was confirmed. An additional two cycles of chemotherapy were given, completing 1 year of treatment, to eradicate residual microscopic disease. Today, after 7 months of close follow-up, the patient is alive and still in complete remission (exceeding 9 months duration), although experiencing mild peripheral neurological toxicity.

\section{Conclusions}

HCC is a deadly disease, with 5-year overall survival below $45 \%$ even when treated by liver transplantation in patients with pTNM stage IVA [19]. Whether current liver transplantation criteria should be expanded is a subject of an ongoing debate, as described earlier. On the other hand, successfully attempting surgical resection in a patient with locally advanced disease is much more challenging, and depends primarily on the surgeon's experience. As we described in our patient, successful surgical resection was made after referral to an experienced center, although the patient was diagnosed and initially deemed inoperable in a small hospital. Another thing we would like to emphasize is that it is well established that radiological and biochemical criteria are sufficient for diagnosis of HCC. We could speculate that the relative inexperience of small centers without a consultant oncologist for diagnosis and treatment of HCC resulted in an unnecessary biopsy, which could be a possible cause of tumor dissemination. We would like to emphasize that a consultant oncologist should be involved in the diagnosis and treatment of patients with cancer from the very beginning, which could prove useful in the improvement of outcomes.

In patients with metastatic disease, treatment options are limited producing modest improvement in overall survival of about 3 months in a minority of patients, even when novel biologic agents are used. Single chemotherapeutic agents which have proven beneficial in terms of response rate higher than $10 \%$ are doxorubicin, 5 -fluorouracil and cisplatin [20].

Polichemotherapy, with the PIAF (cisplatin, interferonalpha, doxorubicin, 5-fluorouracil) regimen most commonly used, has no proven survival benefit over doxorubicin alone, although it doubles the response rates and can result in complete pathohistological responses in patients with initially inoperable $\mathrm{HCC}$ at a price of increased toxicity [21-23]. Since our patient was of excellent performance status and sorafenib was not available for treatment of HCC in our country because it is not covered by the national insurance policy, we decided to try a polichemotherapy regimen, which resulted in durable complete remission. Since no clear benefit of interferon therapy has been shown in patients with metastatic non-viral-related HCC, we treated the patient with a modified ECF regimen $[24,25]$. To the best of our knowledge, this is the first case of complete remission of metastatic HCC in a patient treated with systemic chemotherapy according to the ECF regimen. Only a few complete responses to tegafur and thalidomide-based chemotherapy have been described so far $[26,27]$. Pathological and radiological complete responses are well known to correlate with better progression-free survival and overall survival, which can be supported by our case as well.

Since it has been described that diabetic patients with HCC treated by metformin have a better prognosis, maybe this can be attributed to the response seen in our patient [28]. We could speculate that metformin could be active in HCC either through mTOR (mammalian target of rapamycin) inhibition, or by interfering with the energetic balance of tumor cells by suppression of oxidative phosphorylation via AMPK (5' adenosine monophosphate-activated protein kinase), consequently enhancing the efficiency of chemotherapy in p53-deficient cells $[29,30]$. 
To conclude, surgical resection of borderline resectable tumors should be attempted in patients with excellent performance status in the hands of experienced surgeons, at least until transplantation criteria are revised. Maybe chemotherapy should not be left forgotten as a treatment modality in metastatic HCC, and should probably be offered to patients with excellent performance status in areas where sorafenib is unavailable. Chemotherapy efficiency in combination with metformin should probably be further tested in clinical trials.

\section{Consent}

Written informed consent was obtained from the patient for publication of this Case report and any accompanying images. A copy of the written consent is available for review by the Editor-in-Chief of this journal.

\section{Abbreviations}

AFP: Alpha-fetoprotein; ECF: Epirubicin, cisplatin, and 5-fluorouracil; HCC: Hepatocellular cancer.

\section{Competing interests}

The authors declare that they have no competing interests.

\section{Authors' contributions}

IR drafted the manuscript and gathered the patient data. SB and HG drafted the manuscript, carried out diagnostic studies, and guided the patient therapy. JP, IG, DK, NL and SP were involved in drafting the manuscript. All authors read and approved the final manuscript.

\section{Author details}

'University of Zagreb Faculty of Medicine, Salata 3, 10000, Zagreb, Croatia.

${ }^{2}$ Department of Oncology, Division of Gastrointestinal Malignancies, University Hospital Center Zagreb, Kispaticeva 12, 10000, Zagreb, Croatia.

Received: 26 May 2013 Accepted: 18 September 2013

Published: 22 September 2013

\section{References}

1. Siegel R, DeSantis C, Virgo K, Stein K, Mariotto A, Smith T, Cooper D, Gansler T, Lerro C, Fedewa S, Lin C, Leach C, Cannady RS, Cho H, Scoppa S, Hachey M, Kirch R, Jemal A, Ward E: Cancer treatment and survivorship statistics, 2012. CA Cancer J Clin 2012, 62:220-241.

2. Chen J-D, Yang H-I, lloeje UH, You S-L, Lu S-N, Wang L-Y, Su J, Sun C-A, Liaw Y-F, Chen C-J: Carriers of inactive hepatitis B virus are still at risk for hepatocellular carcinoma and liver-related death. Gastroenterology 2010, 138:1747-1754.

3. Beasley RP, Hwang LY, Lin CC, Chien CS: Hepatocellular carcinoma and hepatitis B virus. A prospective study of 22,707 men in Taiwan. Lancet 1981, 2:1129-1133.

4. Rehermann B, Nascimbeni M: Immunology of hepatitis B virus and hepatitis C virus infection. Nat Rev Immunol 2005, 5:215-229.

5. Yuen M-F, Tanaka Y, Fong DY-T, Fung J, Wong DK-H, Yuen JC-H, But DY-K, Chan AO-O, Wong BC-Y, Mizokami M, Lai C-L: Independent risk factors and predictive score for the development of hepatocellular carcinoma in chronic hepatitis B. J Hepatol 2009, 50:80-88.

6. Yang H-I, Sherman M, Su J, Chen P-J, Liaw Y-F, Iloeje UH, Chen C-J: Nomograms for risk of hepatocellular carcinoma in patients with chronic hepatitis B virus infection. J Clin Oncol 2010, 28:2437-2444.

7. Blum HE, Moradpour D: Viral pathogenesis of hepatocellular carcinoma. J Gastroenterol Hepatol 2002, 17(Suppl 3):S413-S420.

8. Seitz HK, Stickel F: Risk factors and mechanisms of hepatocarcinogenesis with special emphasis on alcohol and oxidative stress. Biol Chem 2006, 387:349-360.
9. Bedogni G, Miglioli L, Masutti F, Tiribelli C, Marchesini G, Bellentani S: Prevalence of and risk factors for nonalcoholic fatty liver disease: the Dionysos nutrition and liver study. Hepatol Baltim Md 2005, 42:44-52.

10. Facciuto ME, Rochon C, Pandey M, Rodriguez-Davalos M, Samaniego S, Wolf DC, Kim-Schluger L, Rozenblit G, Sheiner PA: Surgical dilemma: liver resection or liver transplantation for hepatocellular carcinoma and cirrhosis. Intention-to-treat analysis in patients within and outwith Milan criteria. HPB 2009, 11:398-404.

11. Merchant N, David CS, Cunningham SC: Early hepatocellular carcinoma: transplantation versus resection: the case for liver resection. Int $\mathrm{J}$ Hepatol 2011, 2011:142085.

12. Patel SS, Arrington AK, McKenzie S, Mailey B, Ding M, Lee W, Artinyan A, Nissen N, Colquhoun SD, Kim J: Milan criteria and UCSF criteria: a preliminary comparative study of liver transplantation outcomes in the United States. Int J Hepatol 2012, 2012:253517.

13. Duffy JP, Vardanian A, Benjamin E, Watson M, Farmer DG, Ghobrial RM, Lipshutz G, Yersiz H, Lu DSK, Lassman C, Tong MJ, Hiatt JR, Busuttil RW: Liver transplantation criteria for hepatocellular carcinoma should be expanded. Ann Surg 2007, 246:502-511.

14. Zhu AX: Systemic therapy of advanced hepatocellular carcinoma: how hopeful should we be? Oncologist 2006, 11:790-800.

15. Llovet JM, Ricci S, Mazzaferro V, Hilgard P, Gane E, Blanc J-F, de Oliveira AC Santoro A, Raoul J-L, Forner A, Schwartz M, Porta C, Zeuzem S, Bolondi L, Greten TF, Galle PR, Seitz J-F, Borbath I, Häussinger D, Giannaris T, Shan M, Moscovici M, Voliotis D, Bruix J: Sorafenib in advanced hepatocellular carcinoma. N Engl J Med 2008, 359:378-390.

16. Cheng A-L, Kang Y-K, Chen Z, Tsao C-J, Qin S, Kim JS, Luo R, Feng J, Ye S, Yang T-S, Xu J, Sun Y, Liang H, Liu J, Wang J, Tak WY, Pan H, Burock K, Zou J, Voliotis D, Guan Z: Efficacy and safety of sorafenib in patients in the Asia-Pacific region with advanced hepatocellular carcinoma: a phase III randomised, double-blind, placebo-controlled trial. Lancet Oncol 2009, 10:25-34.

17. Cao H, Phan H, Yang L-X: Improved chemotherapy for hepatocellular carcinoma. Anticancer Res 2012, 32:1379-1386.

18. Jelic S: Hepatocellular carcinoma: ESMO clinical recommendations for diagnosis, treatment and follow-up. Ann Oncol 2009, 20(suppl 4):iv41-iv45.

19. Kaihara S, Ogino S, Akioka S, Okamoto M, Yoshimura N: Indication and current issues in liver transplantation for hepatocellular carcinoma [in Japanese]. Nihon Shokakibyo Gakkai Zasshi 2004, 101:264-268.

20. Lai CL, Wu PC, Chan GC, Lok AS, Lin HJ: Doxorubicin versus no antitumor therapy in inoperable hepatocellular carcinoma. A prospective randomized trial. Cancer 1988, 62:479-483.

21. Lin DY, Lin SM, Liaw YF: Non-surgical treatment of hepatocellular carcinoma. J Gastroenterol Hepatol 1997, 12:S319-S328.

22. Simonetti RG, Liberati A, Angiolini C, Pagliaro L: Treatment of hepatocellular carcinoma: a systematic review of randomized controlled trials. Ann Oncol 1997, 8:117-136.

23. Leung TW, Patt YZ, Lau WY, Ho SK, Yu SC, Chan AT, Mok TS, Yeo W Liew CT, Leung NW, Tang AM, Johnson PJ: Complete pathological remission is possible with systemic combination chemotherapy for inoperable hepatocellular carcinoma. Clin Cancer Res 1999, 5:1676-1681.

24. Rougier P, Mitry E, Barbare J-C, Taieb J: Hepatocellular carcinoma (HCC): an update. Semin Oncol 2007, 34(2 Suppl 1):S12-S20.

25. Boucher E, Corbinais S, Brissot P, Boudjema K, Raoul J-L: Treatment of hepatocellular carcinoma (HCC) with systemic chemotherapy combining epirubicin, cisplatinum and infusional 5-fluorouracil (ECF regimen). Cancer Chemother Pharmacol 2002, 50:305-308.

26. Feng YM, Feng CW, Chen SCC, Hsu CD: Unexpected remission of hepatocellular carcinoma (HCC) with lung metastasis to the combination therapy of thalidomide and cyproheptadine: report of two cases and a preliminary HCC cell line study. BMJ Case Rep 2012. doi:10.1136/bcr2012-007180.

27. Tanabe K, Taura K, Hatano E, Koyama Y, Takada Y, Uemoto S: Complete remission of hepatocellular carcinoma with multiple lung metastases by oral administration of tegafur/uracil. Gan To Kagaku Ryoho 2013, 40:1077-1080

28. Akmal K, Hassabo H, Botrus G, Shah N, Soliman K, Khalaf R, Li D, Kaseb A, Hassan M: Impact of metformin on HCC prognosis [abstract 3549]. Cancer Res 2012, 72(8 Supplement):3594. 
29. Buzzai $M$, Jones RG, Amaravadi RK, Lum JJ, DeBerardinis RJ, Zhao F, Viollet $B$, Thompson CB: Systemic treatment with the antidiabetic drug metformin selectively impairs p53-deficient tumor cell growth. Cancer Res 2007, 67:6745-6752.

30. Smith-Vikos T: A report of the James Watson Lecture at Yale University. Yale J Biol Med 2012, 85:417-419.

doi:10.1186/1477-7819-11-236

Cite this article as: Rados et al:: Successful resection of hepatocellular cancer not amenable to Milan criteria and durable complete remission induced by systemic polichemotherapy after development of metastases - should we think about revising the current treatment guidelines in selected patients? World Journal of Surgical Oncology 2013 11:236.

\section{Submit your next manuscript to BioMed Central and take full advantage of:}

- Convenient online submission

- Thorough peer review

- No space constraints or color figure charges

- Immediate publication on acceptance

- Inclusion in PubMed, CAS, Scopus and Google Scholar

- Research which is freely available for redistribution 